\title{
Chemical composition of the sponge Hymeniacidon sanguinea from the Canary Islands
}

\author{
Jordan Necheva ${ }^{\mathrm{a}}$, William W. Christie ${ }^{\mathrm{b}}$, Rafael Robaina ${ }^{\mathrm{c}}$, Fernando de Diego ${ }^{\mathrm{c}}$, Simeon Popov ${ }^{\mathrm{a}}$, \\ Kamen Stefanov ${ }^{\mathrm{a}, *}$ \\ anstitute of Organic Chemistry with Centre of Phytochemistry, Bulg. Acad. Sci., Sofia 1113, Bulgaria \\ ${ }^{\mathrm{b}}$ The Scottish Crop Research Institute, Invergowrie, Dundee DD2 5DA, Scotland, UK \\ ${ }^{\mathrm{c}}$ University of Las Palmas, 35001 Las Palmas, Gran Canaria, Spain
}

Received 30 May 2003; received in revised form 19 October 2003; accepted 20 October 2003

\begin{abstract}
The fatty acid composition of the lipids from the sponge Hymeniacidon sanguinea was investigated and 73 acids were identified. Three of them were new and their structures, elucidated by gas chromatography/mass spectrometry, were identified as 13-methyl-icosanoic, 15-methyl-docosanoic and 3,13-dimethyl-tetradecanoic. Only 12 sterols were present, with cholestanol predominating in the volatile fraction; 22 compounds were identified, mainly hydrocarbons and fatty acids. In the $n$-butanol fraction, we found mainly nitrogen-containing compounds. The compositions of sterols and lipids in the sponge collected from two locations with different ecological conditions (Canary Islands and Black Sea) were compared.
\end{abstract}

(c) 2003 Elsevier Inc. All rights reserved.

Keywords: Hymeniacidon sanguinea; Sponges; Lipids; Fatty acids; Polar compounds; Sterols; Volatiles; Salinity

\section{Introduction}

Metabolite profiling is one of the major applications of phytochemical analysis to functional genomics. Creating or improving metabolic yield depends on understanding plant metabolism and its regulation (metabolome). Recently such investigations have focussed on terrestrial plants, but few such studies have dealt with marine organisms; as well, the functions of the genes in marine invertebrates are rarely studied.

Lipids and sterols are important constituents of lipid cell membranes and determine their permeability. Their composition depends on marine eco-

\footnotetext{
*Corresponding author. Tel.: + 359-2-9606-135; fax: +3592-8700-225.

E-mail address: kamen@orgchm.bas.bg (K. Stefanov).
}

logical conditions (salinity, temperature, pollution, etc.) and can change to improve the defensive functions of the cell membranes (Aiello et al., 1993; Stone, 1970). For this reason it is of interest to compare the lipid and sterol composition of the widely distributed sponge, Hymeniacidon sanguinea (family Hymeniacidonidae, order Halichondrida), occurring in the Canary Islands and in the Black Sea (Christie et al., 1994; Elenkov et al., 1999). The Black Sea is characterized by half the salinity and lower water temperatures than the Canary Islands region. Differences in the lipid and sterol composition of the sponge from the two collection sites could have adaptive value.

Volatile and polar fractions, extracted from defatted sponges by $n$-butanol, have very complex compositions. There are very limited investigations 
on these fractions in marine invertebrates, contrary to higher plants, where such compounds, especially volatile ones, play an important role for the defense against bacteria, fungi and viruses, and in plantinsect relationships. This is the first investigation on these compounds in Hymeniacidon sp.

Most of the Hymeniacidon species investigated to date possess similar sterol compositions. $\Delta^{5}$ Sterols and stanols are the main groups, but their ratio varies in different species (Elenkov et al., 1999). Two investigations exist on sterols from $H$. sanguinea (Elenkov et al., 1999; Sica et al., 1978) and despite the differences in the ecological conditions (the sponges are collected in the Black Sea and Mediterranean Sea, respectively). No significant differences are noted in their sterol compositions. The main sterols are stanols, with cholestanol accounting for more than $60 \%$ of the total. Probably, sterols in this sponge have no adaptive functions in the cell membranes and the presence of unusually high concentrations of stanols is a taxonomic characteristic of $H$. sanguinea. In order to prove this assumption it is necessary to investigate the sterol composition of at least one more sample of $H$. sanguinea, collected from another sea.

The fatty acid composition of lipids is important for the functions of the cell membranes, and even small changes in the environment often lead to significant changes in the fatty acid composition of lipids. A previous investigation on two other sponges from the Canary Islands revealed some new and unusual fatty acids (Nechev et al., 2002a,b). In the lipids of $H$. sanguinea from the same location 73 fatty acids were identified. Three of these acids, namely 13-methyl-icosanoic, 15methyl-docosanoic and 3,13-dimethyl-tetradecanoic acids have not been found previously in marine organisms and may be new to science.

The purpose of this investigation is to analyze sterols and lipid fatty acids in $H$. sanguinea collected around the Canary Islands and compare them with data obtained previously for Black Sea $H$. sanguinea. This will give some information about the effect of the environment on the components of lipid cell membranes. Also, the investigation on the composition of the volatile and polar metabolites can give valuable information about the biological activity and functions of these metabolites, as well as for the biological equilibrium in the sea.

\section{Materials and methods}

\subsection{Isolation of lipophilic and polar compounds}

Sponges $H$. sanguinea were collected by a scuba diver at depths of 25-35 m near Las Palmas, Gran Canaria, Canary Islands, Spain, in November 2001. At least ten animals were taken for analysis. Samples were washed with fresh water and frozen at $-30{ }^{\circ} \mathrm{C}$ for 1 week. After transport to the laboratory, the sponges were extracted with a mixture of chloroform:methanol $(2: 1 \mathrm{v} / \mathrm{v})$, followed by filtration and addition of an equal volume of water. The lower layer, containing total lipids (lipophilic extract) was evaporated under vacuum at $60{ }^{\circ} \mathrm{C}$. The upper polar fraction was extracted twice with $n$-butanol. The yield of lipophilic extract was $4.4 \%$ of the dry mass of the sponges. The yield of the butanol extract was $0.9 \%$ of the dry mass of the sponges (total dry mass $6.5 \mathrm{~g}$ ).

A voucher specimen was deposited in the University of Las Palmas, Canary Islands, Spain.

\subsection{Preparation of fatty acid methyl esters}

A portion of the total lipid extract $(100 \mathrm{mg}$ ) was transesterified with $15 \%$ acetyl chloride in methanol (Christie, 1989). Fatty acid methyl esters (FAME) were separated by preparative thin layer chromatography (TLC) (plates $20 \times 20 \mathrm{~cm}^{2}$ silica gel G 60 (Merck), layer $0.5 \mathrm{~mm}$, mobile phase hexane-acetone 95:5 v/v).

\subsection{Catalytic hydrogenation}

Fatty acids methyl esters in methanol solution were subjected to catalytic hydrogenation with hydrogen and platinum oxide (Christie, 2003).

\subsection{Gas chromatography/mass spectrometry of fatty acid derivatives}

Part of the lipids were hydrolysed to free fatty acids and converted to picolinyl esters, pyrrolidides and 4,4-dimethyloxazoline (DMOX) derivatives by established methods (Christie, 2003). Derivatives and FAME were submitted to gas chromatography/mass spectrometry (GC/MS), with a Hewlett Packard 5890 Series II plus gas chromatograph attached to a HP model 5989 MS engine. 
The latter was used in the electron impact mode at $70 \mathrm{eV}$ with a source temperature $250{ }^{\circ} \mathrm{C}$. The GC was fitted with on-column injection, and equipped with a capillary column of fused silica coated with DB5-MS ${ }^{\mathrm{TM}}(0.25 \mathrm{~mm} \times 30 \mathrm{~m}, 0.25$ $\mu \mathrm{m}$ film; J.\&W. Scientific, Folsom, CA). After holding the temperature at $80{ }^{\circ} \mathrm{C}$ for $3 \mathrm{~min}$, the column was temperature-programmed at $20{ }^{\circ} \mathrm{C} /$ min to $160{ }^{\circ} \mathrm{C}$, then at $4{ }^{\circ} \mathrm{C} / \mathrm{min}$ to $350{ }^{\circ} \mathrm{C}$, where it was held for $20 \mathrm{~min}$. Helium was the carrier gas.

\subsection{Isolation and analysis of sterols}

Part of the lipophilic extract $(100 \mathrm{mg})$ was chromatographed on a silica gel column $(10 \mathrm{~g})$ with mixtures of hexane and acetone in ascending polarity. The fractions, containing sterols according to TLC were combined and purified by preparative TLC with hexane-acetone 9:1 as mobile phase. The sterols obtained $(3 \mathrm{mg})$ were analysed by GC and by GC/MS. A GC Pye Unicam 304 (Scientific Instrument Company of Philips, Cambridge, England) equipped with a flame ionization detector and a capillary column SPB-1 $(30 \mathrm{~m} \times 0.32 \mathrm{~mm}$, $0.25 \mu \mathrm{m}$ film thickness, Supelco Park, Bellefonte, PA) was used. The temperature programme was $230-300{ }^{\circ} \mathrm{C}$ at $4{ }^{\circ} \mathrm{C} / \mathrm{min}$ and a 10 -min hold. The injector temperature was $300{ }^{\circ} \mathrm{C}$ and the detector temperature was $320{ }^{\circ} \mathrm{C}$; the carrier gas was nitrogen.

A GC/MS Hewlett Packard 6890+MS 5973 (Hewlett Packard, Palo Alto, CA) with a capillary column SPB-50 $(30 \mathrm{~m} \times 0.32 \mathrm{~mm}, 0.25 \mu \mathrm{m}$ film thickness, Supelco Park) was used. The carrier gas was helium and a temperature programme of 270$290{ }^{\circ} \mathrm{C}$ at $4{ }^{\circ} \mathrm{C} / \mathrm{min}$ and a 20 -min hold was used. The ion source was set at $250{ }^{\circ} \mathrm{C}$ and the ionisation voltage was $70 \mathrm{eV}$.

\subsection{Isolation and analyses of volatile compounds}

Part of the lipophilic extract $(100 \mathrm{mg})$ was subjected to a 4-h distillation-extraction in a Lickens-Nickerson apparatus (Hendriks et al., 1981). Volatiles were extracted from the distillate with diethyl ether (yield: $3 \mathrm{mg}$ ) and investigated by analytical GC/MS Hewlett Packard $6890+$ MS 5973 with a capillary column HP5-MS (30 $\mathrm{m} \times 0.25 \mathrm{~mm}, 0.25 \mu \mathrm{m}$ film thickness). The tem- perature was programmed from 40 to $280{ }^{\circ} \mathrm{C}$ at a rate of $6{ }^{\circ} \mathrm{C} / \mathrm{min}$. Helium was used as a carrier gas.

\subsection{Isolation and analysis of the n-butanol fraction}

The $n$-butanol fraction was isolated as described above. A 5-mg aliquot was dissolved in $50 \mu \mathrm{l}$ pyridine and $75 \mu \mathrm{l}$ of bis-(trimethylsilyl)-trifluoroacetamide was added. The mixture was heated at $80{ }^{\circ} \mathrm{C}$ for $30 \mathrm{~min}$ and analysed by GC/MS as described above, but equipped with a capillary column HP-5 ( $23 \mathrm{~m} \times 0.2 \mathrm{~mm}, 0.5 \mu \mathrm{m}$ film thickness). Helium was used as a carrier gas with a temperature programme $100-315^{\circ} \mathrm{C}$ at $5{ }^{\circ} \mathrm{C} / \mathrm{min}$ and a 10-min hold.

\section{Results and discussion}

\subsection{Fatty acids}

A significant number of fatty acids was identified in both samples. Total extracts were purified according to the method of Bligh and Dyer (1959), the lipids obtained saponified and the fatty acids methylated with $5 \%$ acetyl chloride in dry methanol (Christie, 1989). The esters obtained were analysed by GC/MS as picolinyl esters (Balazy and Nies, 1989), although data from DMOX derivatives (Fay and Richli, 1991) and pyrrolidides (Christie, 2003) provided confirmation of most structures. The data obtained are summarized in Table 1.

It is evident that, analogously to the sterols, the sponges from the Black Sea and the Canary Islands do not show significant differences in their fatty acid composition. In both samples the main fatty acids are 16:0, 9-16:1, 13-methyl-14:0 and 18:0. Nevertheless, there are some differences between the two sponges: $H$. sanguinea from the Black Sea contains much more 4,8,12-trimethyl-13:0, 9,1218:2 and 5,8,11,14,17-20:5 acid. The sponge from the Canary Islands contained relatively higher concentrations of 11-methyl-18:0, 7,10,13,16-22:4 and 23-methyl-24:2, which are absent in the Black Sea sponge.

In general, the sample from the collection spot with higher salinity (Canary Islands) contains a larger diversity of fatty acids. The water temperature in the Canary Islands ranges from 17 to 24 ${ }^{\circ} \mathrm{C}$. By the time of collection we have the highest temperature peaks, as wind is absent and anticy- 
clone weather is, therefore, dominant. Acids, containing a cyclopropane ring were found only in the Canary Islands sponge. This fact, as well as the significant differences in the structures and relative concentrations of the alkylated fatty acids and acids containing an odd number of carbon atoms is in agreement with the above suggestion that the symbiotic bacteria in the two species are different. It is known that organisms, inhabiting colder waters, contain more unsaturated fatty acids. The Black Sea is much colder than the Canary Islands region, but concentration of the saturated fatty acids in both the investigated samples is practically identical ( $\sim 40 \%$ from the total fatty acids). In such a case, adaptation of the sponges to colder waters must be realized by an increase in the biosynthesis of polyunsaturated fatty acids. In fact, they are present in much higher concentrations in the Black Sea sponge, especially acids containing 18-22 carbon atoms and 4 or 5 double bonds. 5,15-Dimethyl-24:2 and trans-6-16:1 acids were only found in $H$. sanguinea from the Black Sea.

H. sanguinea from the Canary Islands contains three fatty acids which, to the best of our knowledge, have not been found before in sponges and may even be new to science.

Fig. 1 represents the mass spectra of the methyl ester (above) and the picolinyl ester (below) of the novel 13-methyl-20:0 acid. The molecular ion has relatively high intensity- $40 \%$ in FAME spectra and $12 \%$ in picolinyl derivative. The base peak in the methyl ester spectrum at $m / z=74$ is due to the McLafferty rearrangement and the next intensive peak at $m / z=87$ is due to cleavage between $\mathrm{C}_{3}$ and $\mathrm{C}_{4}$. The corresponding peaks in the spectrum of the picolinyl derivative were $m / z=151$ and 164. It was easy to locate the methyl group in the spectrum of FAME from the gaps of $28 \mathrm{amu}$ between $m / z=213$ and 241. Similarly, for the picolinyl esters, the corresponding gap was between $m / z=290$ and 318 .

In Fig. 2, the mass spectrum of the methyl ester of the novel 15-methyl-22:0 acid (above) is shown together with its picolinyl ester (below). Its structure is most easily determined from the picolinyl ester derivative, where the gap of 28 amu between $m / z=318$ and 346 is absolutely diagnostic.

In Fig. 3, the mass spectrum of the picolinyl ester of the third novel acid, 3,13-dimethyl-14:0, is shown. In this instance the gaps of $27 / 28 \mathrm{amu}$ between $\mathrm{m} / z=151$ and 178 , and between $\mathrm{m} / \mathrm{z}=$
Table 1

Fatty acid composition (wt.\% of the total) of the sponge $H$. sanguinea

\begin{tabular}{|c|c|c|}
\hline \multirow{2}{*}{ Fatty acid ${ }^{\mathrm{a}}$} & \multicolumn{2}{|c|}{ H. sanguinea wt. $\%^{\mathrm{b}}$} \\
\hline & Canary Islands & $\begin{array}{l}\text { Black Sea } \\
\text { (Christie et al., } \\
\text { 1994) }\end{array}$ \\
\hline 10:0 & 0.2 & - \\
\hline 11:0 & 0.1 & - \\
\hline $12: 0$ & 0.3 & Trace \\
\hline i-Me-12:0 & - & Trace \\
\hline $13: 0$ & 0.1 & - \\
\hline i-Me-13:0 & 0.3 & 0.3 \\
\hline $14: 0$ & 1.4 & 2.5 \\
\hline 4,8,12-tri-Me-13:0 & 0.9 & 9.7 \\
\hline $7-14: 1$ & - & 0.1 \\
\hline $9-14: 1$ & - & Trace \\
\hline i-Me-14:0 & 2.5 & 3.1 \\
\hline ai-Me-14:0 & 1.8 & 0.4 \\
\hline 13-Me-4-14:1 & - & 0.5 \\
\hline i-Me-15:0 & 1.4 & 2.0 \\
\hline ai-Me-15:0 & 0.6 & 1.9 \\
\hline 3,13-di-Me-14:0 $0^{c}$ & 0.4 & - \\
\hline $15: 0$ & 0.7 & 0.9 \\
\hline 5,9,13-tri-Me-14:0 & - & Trace \\
\hline $5,9-16: 2$ & - & Trace \\
\hline $7-16: 1$ & - & 0.9 \\
\hline $9-16: 1$ & 5.8 & 6.5 \\
\hline $11-16: 1$ & 1.2 & 0.4 \\
\hline $16: 0$ & 7.2 & 8.7 \\
\hline i-Me-9-16:1 & - & 0.2 \\
\hline ai-Me-6-16:1 & - & Trace \\
\hline 10-Me-16:0 & 1.34 & Trace \\
\hline i-Me-16:0 & 0.8 & 1.4 \\
\hline ai-Me-16:0 & 0.8 & 1.6 \\
\hline 13-Me-16:0 & - & Trace \\
\hline 7,8-di-Me-7-15:1 & - & 0.5 \\
\hline Trans-6-16:1 & - & 0.1 \\
\hline $9,12-16: 2$ & - & Trace \\
\hline 9,10-cyclopropyl-16:0 & 0.1 & Trace \\
\hline $4,7,10-16: 3$ & - & 0.2 \\
\hline $9-17: 1$ & 1.3 & 0.2 \\
\hline $17: 0$ & 0.8 & 0.5 \\
\hline Phytanic acid & 0.5 & Trace \\
\hline 14-Me-17:0 & - & 0.3 \\
\hline $4,7,10,13-16: 4$ & - & 0.6 \\
\hline 14-Me-5-17:1 & - & 0.1 \\
\hline i-Me-9-17:1 & - & 0.1 \\
\hline $5,9-17: 2$ & - & Trace \\
\hline i-Me-17:0 & 0.3 & - \\
\hline $9-18: 1$ & 5.1 & 3.0 \\
\hline 11-18:1 & 0.9 & 6.1 \\
\hline $18: 0$ & 2.5 & 3.5 \\
\hline 11-Me-18:0 & 3.5 & - \\
\hline 10-Me-18:0 & - & Trace \\
\hline i-Me-18:0 & 0.5 & 0.1 \\
\hline ai-Me-18:0 & 0.6 & Trace \\
\hline $9,12-18: 2$ & - & 1.6 \\
\hline $5,11-18: 2$ & - & 0.2 \\
\hline $11,14-18: 2$ & - & Trace \\
\hline $6,9,12-18: 3$ & - & 0.4 \\
\hline 11,12-cyclopropyl-18:0 & 1.3 & Trace \\
\hline $6,9,12,15-18: 4$ & 0.35 & 0.9 \\
\hline 19:0 & 0.4 & 0.4 \\
\hline $9,12,15-18: 3$ & - & 1.0 \\
\hline i-Me-19:0 & 0.4 & 0.8 \\
\hline $3,6,9,12,15-18: 5$ & - & 1.3 \\
\hline $5,8,11,14-20: 4$ & 1.25 & 2.7 \\
\hline
\end{tabular}


Table 1 (Continued)

\begin{tabular}{|c|c|c|}
\hline \multirow[t]{2}{*}{ Fatty acid ${ }^{\mathrm{a}}$} & \multicolumn{2}{|c|}{ H. sanguinea wt. $^{\mathrm{b}}$} \\
\hline & Canary Islands & $\begin{array}{l}\text { Black Sea } \\
\text { (Christie et al., } \\
\text { 1994) }\end{array}$ \\
\hline $8,11,14,17-20: 4$ & - & Trace \\
\hline $5,8,11,14,17-20: 5$ & 0.7 & 3.8 \\
\hline $8,11,14-20: 3$ & - & 0.2 \\
\hline $11,14,17-20: 3$ & - & 0.1 \\
\hline $5,11-20: 2$ & 0.1 & 0.2 \\
\hline $5,13-20: 2$ & - & 0.2 \\
\hline $8,11-20: 2$ & - & Trace \\
\hline $7,13-20: 2$ & - & Trace \\
\hline $10,13-20: 2$ & - & Trace \\
\hline $11,14-20: 2$ & 0.2 & 0.1 \\
\hline 11-20:1 & 4.6 & 0.1 \\
\hline $7-20: 1$ & - & 0.4 \\
\hline $13-20: 1$ & - & 0.2 \\
\hline $20: 0$ & 0.8 & 1.0 \\
\hline $13-\mathrm{Me}-20: 0^{\mathrm{c}}$ & 0.6 & - \\
\hline 17-Me-20:0 & - & Trace \\
\hline i-Me-20:0 & 0.2 & 0.3 \\
\hline ai-Me-20:0 & 0.5 & Trace \\
\hline $21: 0$ & 1.1 & 0.5 \\
\hline 18-Me-21:0 & - & Trace \\
\hline ai-Me-21:0 & - & Trace \\
\hline i-Me-21:0 & - & Trace \\
\hline $22: 0$ & 3.9 & 0.2 \\
\hline $5,9-23: 2$ & 0.3 & - \\
\hline $7,13-22: 2$ & 0.5 & 0.2 \\
\hline $7,15-22: 2$ & - & 0.2 \\
\hline $13,16-22: 2$ & - & Trace \\
\hline $5,8,11,14-21: 4$ & - & Trace \\
\hline $13-22: 1$ & - & 0.2 \\
\hline $15-22: 1$ & 0.9 & Trace \\
\hline $17-22: 1$ & - & Trace \\
\hline $10,13,16-22: 3$ & - & 0.1 \\
\hline $15-\mathrm{Me}-22: 0^{\mathrm{c}}$ & 0.9 & - \\
\hline i-Me-22:0 & 0.8 & - \\
\hline $16-23: 1$ & - & 0.1 \\
\hline $7,10,13,16-22: 4$ & 2.4 & 0.2 \\
\hline $23: 0$ & 0.6 & Trace \\
\hline i-Me-23:0 & 0.3 & - \\
\hline ?-Me-5,9-24:2 & 0.6 & - \\
\hline $4,7,10,13,16-22: 5$ & - & 0.9 \\
\hline $7,10,13,16,19-22: 5$ & 0.3 & 7.5 \\
\hline $4,7,10,13,16,19-22: 6$ & - & 0.1 \\
\hline $5,9-24: 2$ & 4.6 & - \\
\hline $5,15-24: 2$ & - & Trace \\
\hline $15,18-24: 2$ & - & Trace \\
\hline $5,9,17-24: 3$ & 1.2 & - \\
\hline $15-24: 1$ & 1.5 & - \\
\hline $17-24: 1$ & 2.1 & 1.4 \\
\hline i-Me-5,9-24:2 & 8.2 & - \\
\hline ai-Me-5,9-24:2 & 0.3 & - \\
\hline 24:0 & 0.6 & Trace \\
\hline $5,9-25: 2$ & 1.4 & 0.5 \\
\hline $9-25: 1$ & - & 0.1 \\
\hline $18-25: 1$ & - & 0.1 \\
\hline $5,9,19-26: 3$ & 1.4 & 3.0 \\
\hline i-Me-5,9-25:2 & 1.2 & - \\
\hline $5,9-26: 2$ & 3.7 & 3.5 \\
\hline $9,19-26: 2$ & - & Trace \\
\hline $17,20-26: 2$ & - & 0.2 \\
\hline $5,9-27: 2$ & 0.3 & Trace \\
\hline $9-26: 1$ & 0.3 & 0.2 \\
\hline $17-26: 1$ & 0.7 & 0.1 \\
\hline $26: 0$ & 0.2 & - \\
\hline
\end{tabular}

Table 1 (Continued)

\begin{tabular}{lll}
\hline Fatty acid $^{\mathrm{a}}$ & \multicolumn{2}{l}{ H. sanguinea $\mathrm{wt}^{\mathrm{b}} \mathrm{b}$} \\
\cline { 2 - 3 } & Canary Islands & $\begin{array}{l}\text { Black Sea } \\
\text { (Christie et al., } \\
\text { 1994) }\end{array}$ \\
\hline i-Me-5,9,17-26:3 & 0.6 & - \\
$5,9,19-27: 3$ & - & Trace \\
$5,9,19-28: 3$ & 3.5 & 2.2 \\
$5,9-28: 2$ & 0.3 & Trace \\
\hline
\end{tabular}

${ }^{a}$ A shorthand designation is used, e.g. 5,9-26:2 means $\Delta 5,9$-hexacosadienoic acid.

${ }^{\mathrm{b}}$ Triplicate values for methyl esters in standard mixture by gas chromatographic analyses varied within $12 \%$ for minor components $(<5 \%$ content) and within $5 \%$ for the others.

${ }^{\mathrm{c}}$ Not previously recognised in sponges.

304 and 332 are diagnostic for the methyl branches in positions 3 and 13, respectively.

Two of the new acids, 13-methyl-20:0 and 15methyl-22:0 are presumably derived by an elongation of 11-methyl-18:0, which is a major component in the sample and a common component of bacterial lipids. The third new fatty acid, 3,13-dimethyl-14:0, could be due to a bacterial symbiont. A similar acid, 4,13-dimethyl-14:0, was isolated from halophytic bacteria from salt pans of Burgas in Bulgaria (Carballeira et al., 2001).

An interesting characteristic of sponge lipids is the presence of acids with longer chains, containing up to 30 carbon atoms. As expected, both sponge samples contain acids with 23-28 carbon atoms, but their concentration is much higher in the sample from the Canary Islands, possibly connected with the differences in the salinity or water temperatures between the two sampling sites.

\subsection{Sterols}

Sterols were isolated by column chromatography of the total extract, purified by TLC and analyzed by GC/MS. The data obtained were compared with those for Black Sea $H$. sanguinea sterols (Table 2). Great similarities are evident between the sterol compositions of the two samples. Stanols are the main components of the sterol mixtures investigated ( $78 \%$ of the total sterols in the Canary Islands sample and $87 \%$ for the Black Sea sample). They are accompanied by low concentrations of $\Delta^{5}$-sterols. The stanols must be produced by reduction of dietary sterols containing C-5 double bond. This reduction can be performed by the sponge itself or by some symbiotic bacteria, which are characteristic of sponges. Our results cannot distin- 

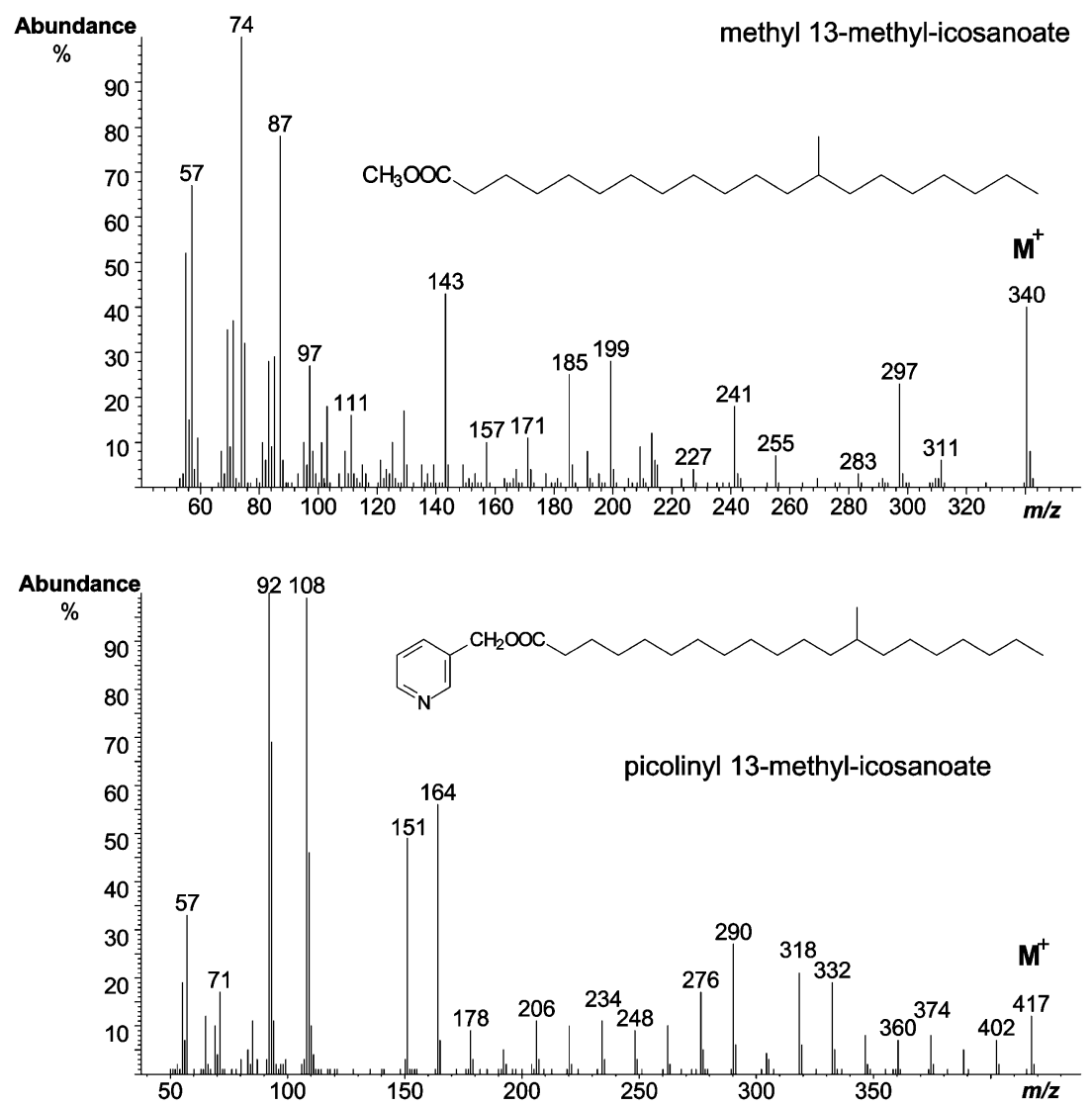

Fig. 1. Mass spectrum of 13-methyl-icosanoic acid as a methyl ester (top) and picolinyl derivative (bottom).

guish between these two possibilities, but the similarity in the reduction rate of $\Delta^{5}$-sterols in the Black Sea, Mediterranean Sea and Atlantic Ocean implies little chance for the sponge symbionts to be identical at three different locations. Probably, the sponge organism reduce the dietary sterols in order to satisfy some cell membrane requirements.

The main sterol was cholestanol, accompanied by some phytoplankton sterols (24-methyl-cholesta5,22-dien-3 $\beta$-ol and 24-methyl-cholesta-5,24(28)-

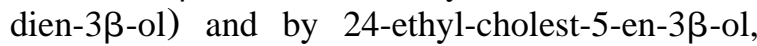
which can come from phytoplankton and/or macroalgae (e.g. Cladophora sp.). This composition is an indication that the diet of $H$. sanguinea independently of the collection site includes mainly zooplankton with phytoplankton and macroalgae accounting far a small part of the diet.

Sterols containing 26 carbon atoms were found only in the Black Sea sample. This is in accordance with our hypothesis (Milkova et al., 1980) that the producer of these sterols, probably phytoplankton, is spread mainly in colder waters.

While sterols containing 26 and 27 carbon atoms were found mainly as stanols, the sterols, alkylated at $\mathrm{C}-24$ suffer lower reduction in the ring system. The position of the double bonds in the side chain also changes the reduction rate. The last depends also on the collection site (Kanazawa et al., 1979; Sica et al., 1978; Erdman and Thomson, 1972).

\subsection{Volatile compounds}

The volatile fraction, produced by steam distillation, appeared to be of limited interest. It contains mainly straight chain saturated hydrocarbons, followed by some free fatty acids (Table 3 ). The similarity in the concentrations of the hydrocarbons with odd and even number of carbon atoms is an indication for the presence of a significant 

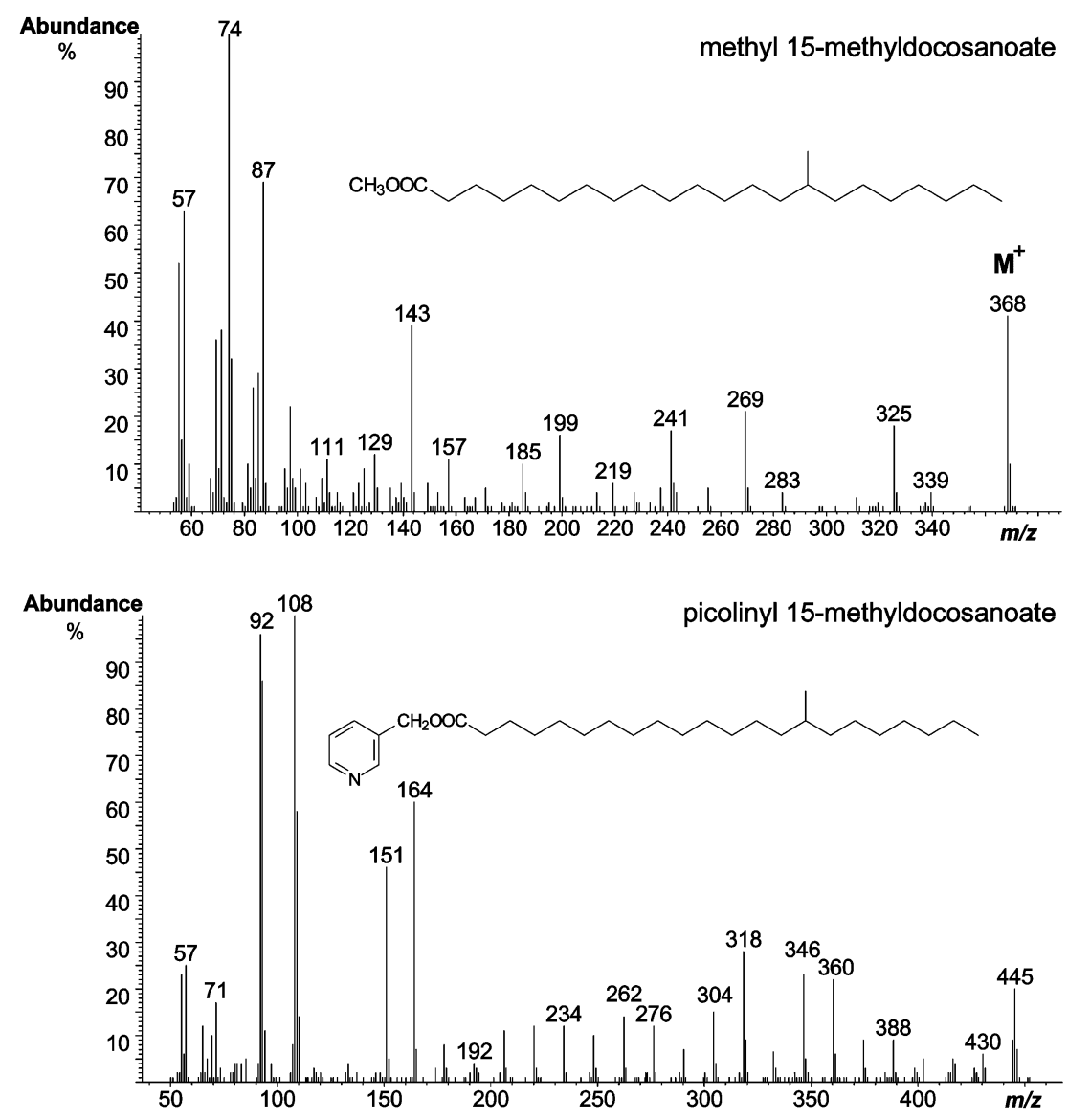

Fig. 2. Mass spectrum of 15-methyl-docosanoic acid as a methyl ester (top) and picolinyl derivative (bottom).

amount of bacteria in $H$. sanguinea from the Canary Islands. Contrary to most of the other marine organisms, especially algae, the investigated sponge contains only one ester of a fatty acid.

\subsection{Polar fraction}

Analogously to the other investigated marine invertebrates, the $n$ - $\mathrm{BuOH}$ fraction contains some

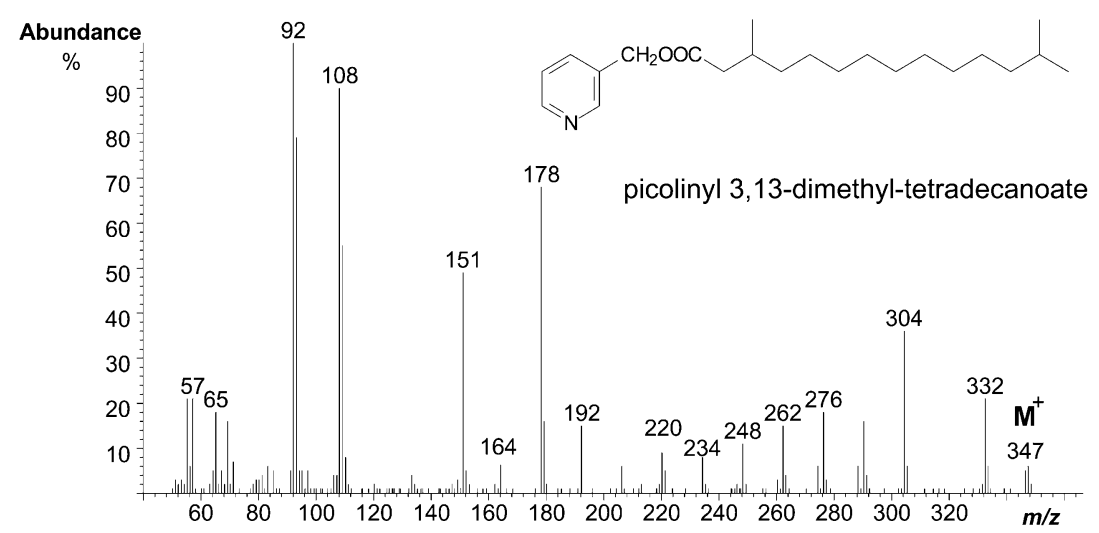

Fig. 3. Mass spectrum of 3,13-dimethyl-tetradecanoic acid as a picolinyl ester. 
Table 2

Sterol composition (\% of the total sterols) of the sponge $H$. sanguinea

\begin{tabular}{|c|c|c|}
\hline \multirow[t]{2}{*}{ Sterols ${ }^{\mathrm{a}}$} & \multicolumn{2}{|l|}{ H. Sanguinea } \\
\hline & Canary Islands & Black Sea (Elenkov et al., 1999) \\
\hline 24-Nor-cholest-22-en-3 $\beta$-ol & - & $1.6 \pm 0.15$ \\
\hline 26-Nor-24-methyl-cholest-22-en-3 $\beta$-ol & - & $1.3 \pm 0.1$ \\
\hline $24-$ Nor-cholesta-5,22-dien-3 $\beta$-ol & - & $0.6 \pm 0.04$ \\
\hline (22Z)-Cholesta-5,22-dien-3 $\beta$-ol & $0.4 \pm 0.02$ & - \\
\hline 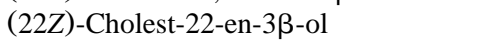 & $0.4 \pm 0.02$ & - \\
\hline$(22 E)$-Cholest-22-en-3 $\beta$-ol & $3.4 \pm 0.4$ & - \\
\hline Cholest-22-en-3 $\beta$-ol & - & $5.2 \pm 0.6$ \\
\hline Cholest-5-en-3 $\beta$-ol & $5.1 \pm 0.5$ & $1.4 \pm 0.16$ \\
\hline 24-Methyl-cholesta-5,22-dien-3 $\beta$-ol & $8.9 \pm 0.8$ & $3.5 \pm 0.3$ \\
\hline $5 \alpha$-Cholestan-3 $\beta$-ol & $68.8 \pm 6.1$ & $63.9 \pm 5.9$ \\
\hline 24-Methyl-cholesta-5,24(28)-dien-3ß-ol & $2.0 \pm 0.1$ & $0.3 \pm 0.02$ \\
\hline 24-Methyl-cholest-22-en-3 $\beta$-ol & - & $7.4 \pm 0.6$ \\
\hline 24-Methyl-cholest-24(28)-en-3 $\beta$-ol & $2.3 \pm 0.2$ & $2.8 \pm 0.25$ \\
\hline 24-Ethyl-cholesta-5,22-dien-3 $\beta$-ol & - & $2.0 \pm 0.2$ \\
\hline 24-Methyl-cholestan-3 $\beta$-ol & $2.0 \pm 0.2$ & $2.7 \pm 0.3$ \\
\hline 24-Ethyl-cholesta-5,22-dien-3 $\beta$-ol & $1.6 \pm 0.15$ & - \\
\hline 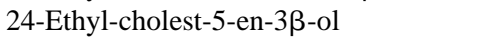 & $4.5 \pm 0.4$ & $4.1 \pm 0.4$ \\
\hline 24-Ethyl-cholesta-5,24(28)-dien-3 $\beta$-ol & - & $0.6 \pm 0.03$ \\
\hline 24-Ethyl-cholestan-3 $\beta$-ol & $0.6 \pm 0.04$ & $0.6 \pm 0.05$ \\
\hline
\end{tabular}

${ }^{\mathrm{a}} \mathrm{Wt} . \%$ of total sterols \pm S.D. from three parallel GC-analyses.

amounts of free fatty acids and their oxidized derivatives (Table 4). Such compounds possess defensive functions (Kanias et al., 1992). Indole5-carboxylic acid and dehydroabietic acid are unusual for marine organisms and might have some defensive functions or have some control function in metabolism (Takami et al., 1998; Varnavas et al., 2003). These compounds might be used as taxonomic markers for $H$. sanguinea. Phosphoric acid is unambiguously a defensive agent, due to its antibacterial and antifungal activity (Cowan, 1999).

Nitrogen-containing compounds are the main constituents of the polar fraction. They belong to two groups-free amino acids and heterocyclic compounds (nucleosides). Free amino acids have been found in most marine invertebrates investigated and are probably precursors of proteins or are a result of their catabolism. We cannot exclude other functions of these compounds, because if they are only a result of biosynthesis and/or of catabolism of proteins they must have a more variable composition. Seven free amino acids have been identified, the main one being the rare 5oxoproline, which appeared to be characteristic of almost all marine invertebrates investigated by us.

The main components of the polar fraction appeared to be urea and some N-containing het-
Table 3

Composition of the volatile compounds in $H$. sanguinea

\begin{tabular}{lr}
\hline & $\%^{\mathrm{a}}$ \\
\hline Acids & \\
i-Me-14:0 & 2.8 \\
Pentadecanoic acid & 4.5 \\
Hexadecenoic acid & 10.4 \\
Hexanedioic acid & 14.3 \\
Hydrocarbons & \\
Hexadecane (16:0) & 2.6 \\
Heptadecane (17:0) & 2.0 \\
Octadecane (18:0) & 2.6 \\
Icosane (20:0) & 1.7 \\
Henicosane (21:0) & 3.2 \\
Docosane (22:0) & 3.3 \\
Tricosane & 3.3 \\
Hydrocarbon & 3.1 \\
Hexacosane & 4.3 \\
Heptacosane & 5.0 \\
Octacosane & 5.6 \\
Nonacosane & 6.0 \\
Triacontane & 5.5 \\
Hentriacontane & 4.9 \\
Alcohols & \\
1-Phenyl ethyl phenol & \\
Esters & 2.7 \\
Hexadecanoic acid (Me ester) & \\
\hline The ion curent gennat & 4.3 \\
\hline
\end{tabular}

The ion current generated depends on the characteristics of the compound and is not a true quantification.

${ }^{\mathrm{a}}$ From total volatiles. 
Table 4

Composition of the polar fraction of $H$. sanguinea

\begin{tabular}{lr}
\hline & $\%^{\mathrm{a}}$ \\
\hline Acids & \\
2-Hydroxy-propanoic acid & 3.6 \\
2-Oxo-3-hydroxy-propanoic acid & 0.5 \\
2-Hydroxy-acetic acid & 1.0 \\
2,3,4-Tri-hydroxy-butyric acid & 0.8 \\
Indole-5-carboxylic acid & 1.6 \\
Hexadecanoic acid (16:0) & 1.9 \\
Octadecanoic acid (18:0) & 0.7 \\
Dehydro-abietic acid & 1.2 \\
Alcohols & \\
Glycerol & 0.8 \\
2-Methyl-1,3-dihydroxy propane & 1.3 \\
N-containing & \\
Alanine & 2.1 \\
Glycine & 1.4 \\
Valine & 2.9 \\
Leucine & 2.2 \\
Urea & 8.7 \\
Isoleucine & 2.9 \\
5-Oxo-proline & 3.5 \\
Uridine & 2.0 \\
Phenylalanine & 3.8 \\
2,4-Dihydroxy-pyrimidine & 0.7 \\
5-Methyl-2,4-dihydroxy-pyrimidine & 3.2 \\
2-Amino-purine & 4.9 \\
Hypoxanthine & \\
Adenosine & \\
\hline
\end{tabular}

The ion current generated depends on the characteristics of the compound and is not a true quantification.

${ }^{\text {a }}$ From total silylated compounds.

erocyclic compounds. All of these are characteristic of marine invertebrates, but the concentrations of some, especially 5-methyl-2,4-dihydroxy-pyrimidine and urea are unusually high and might be used as chemotaxonomic markers. These compounds are evidently not connected with the diet and probably possess some important functions in the metabolism of $H$. sanguinea. They are found relatively rarely in sponges and are an indication of some peculiarities in the metabolism of $H$. sanguinea.

\section{Acknowledgments}

Partial support by the National Foundation for Scientific Research of Bulgaria (Contract X-1101) and by the Scottish Executive Environmental and Rural Affairs Department are gratefully acknowledged.

\section{References}

Aiello, A., Fattorusso, E., Menna, M.L., Pansini, M., 1993. The chemistry of three species of demospongiae collected from the lagoon of Venice: a comparison with some ecological implications. Biochem. Syst. Ecol. 21, 655-660.

Balazy, M., Nies, A.S., 1989. Characterization of epoxides of polyunsaturated fatty acids and GC-mass spectrometry in the analysis of fatty acids. In: Cambie, R.C. (Ed.), Fats for the Future. Ellis Horwood Ltd, Chichester, pp. 335-344.

Bligh, E.G., Dyer, W.J., 1959. A rapid method of total lipid extraction and purification. Can. J. Biochem. Physiol. 37, 911-917.

Carballeira, N.M., Miranda, C., Lozano, C.M., et al., 2001. Characterization of novel methyl-branched chain fatty acids from a halophilic Bacillus species. J. Nat. Prod. 64, 256-259.

Christie, W.W., Brechany, E.Y., Marekov, I.N., Stefanov, K.L., Andreev, S.N., 1994. The fatty acids of the sponge Hymeniacidon sanguinea from the Black Sea. Comp. Biochem. Physiol. B 109, 245-252.

Christie, W.W., 1989. Gas Chromatography and Lipids. Oily Press, Ayr, pp. 67.

Christie, W.W., 2003. Lipid Analysis. third ed.. Bridgwater, Somerset, pp. 215-220.

Cowan, M.M., 1999. Plant products as antimicrobial agents. Clin. Microbiol. Rev. 12, 564-582.

Elenkov, I., Popov, S., Andreev, S., 1999. Sterol composition of the Black Sea sponge Hymeniacidon sanguinea (Grant) and Halichondria panicea (Pallas). Z. Naturforsch., Part C 54, 972-976.

Erdman, T.R., Thomson, R.H., 1972. Sterols from the sponges Cliona celata Grant and Hymeniacidon perleve Montagu. Tetrahedron 28, 5163-5173.

Fay, L., Richli, U., 1991. Location of double bonds in polyunsaturated fatty acids by GC-MS after 4,4-dimethyloxazoline derivatization. J. Chromatogr. 541, 89-98.

Hendriks, H., Geerts, J., Malingre, Th., 1981. The occurrence of valeranone and cryptofauronol in the essential oil of Valeriana officinalis L. S. 1. collected in the northern part of The Netherlands. Pharm. Weekblad, Sci. Edition, 116, 1316-1320.

Kanazawa, A., Teshima, S.-I., Hyodo, S.-I., 1979. Sterols of the sponges (porifera, class demospongiae). Comp. Biochem. Physiol. B 62, 521-525.

Kanias, G.D., Skaltsa, H., Tsitsa, E., Loukis, A., Bitis, J., 1992. Study of the correlation between trace elements, sterols and fatty acids in brown algae from the Saronikos Gulf of Greece. Fresenius J. Anal. Chem. 344, 334-339.

Milkova, Ts., Popov, S., Marekov, N., Andreev, St., 1980. Sterols from Black Sea invertebrates. I. Sterols from Scyphozoa and Anthozoa (Coelenterata). Comp. Biochem. Physiol. B 67, 633-638.

Nechev, J.T., Christie, W.W., Robaina, R., et al., 2002. Chemical composition of the sponge Chondrosia reniformis from the Canary Islands. Hydrobiologia 489, 91-98.

Nechev, J.T., Christie, W.W., Robaina, R., de Diego, F.M., Popov, S.S., Stefanov, K.L., 2002. Lipid composition of the sponge Verongia aerophoba from the Canary Islands. Eur. J. Lipid. Sci. Technol. 104, 800-807. 
Sica, D., De Simone, F., Ramundo, E., Zollo, F., 1978. Sterols from some sponges. Biochem. Syst. Ecol. 6, 77-79.

Stone, A.R., 1970. Seasonal variation in the gross biochemical composition of Hymeniacidon perleve (Montagu). J. Exp. Mar. Biol. Ecol. 5, 265-271.

Takami, H., Kishibayashi, N., Ishii, A., Kumazawa, T., 1998. Indolic and benzimidazole derivatives and steroid $5 \alpha$-reduc- tase inhibitors in the rat prostate. Bioorg. Med. Chem. 6, 2441-2448.

Varnavas, A., Lassiani, L., Valenta, V., Berti, F., Mennuni, L., Makovec, F., 2003. Anthranilic derivatives: a new class of non-peptide $\mathrm{CCK}_{1}$ receptor antagonists. Bioorg. Med. Chem. $11,741-751$. 